\title{
Qualidade pós-colheita de Physalis sob temperatura ambiente e refrigeração
}

\author{
Cláudia Simone Madruga Lima', Joseana Severo², Suélen Braga de Andrade ${ }^{3}$, Luana Borges Affonso , \\ Cesar Valmor Rombaldi ${ }^{5}$ Andrea De Rossi Rufato ${ }^{5}$
}

\section{RESUMO}

A physalis (Physalis peruviana) é um pequeno fruto cujo cultivo vem se expandindo no Brasil. No entanto, informações a respeito do seu armazenamento ainda são escassas. Por isso, o objetivo deste trabalho foi avaliar a qualidade de physalis durante o armazenamento, sob temperaturas ambiente e refrigerada. A colheita foi realizada quando o cálice dos frutos apresentava coloração amarelo-esverdeada, sendo os frutos submetidos aos seguintes tratamentos: 1- armazenamento à temperatura de $20^{\circ} \mathrm{C}\left( \pm 0,5^{\circ} \mathrm{C}\right)$ e 2- armazenamento à temperatura de $4^{\circ} \mathrm{C}\left( \pm 0,5^{\circ} \mathrm{C}\right)$. Foram avaliados os teores de SS, AT, SS/AT, o pH, a firmeza, a cor e a perda de massa dos frutos, a cada dois dias, durante oito dias. Foi possível observar que o emprego da refrigeração promoveu a manutenção da firmeza, auxiliando também na prevenção da perda de massa fresca, do fruto e do cálice. O teor de sólidos solúveis (SS) reduziu-se significativamente, independentemente da temperatura de armazenamento dos frutos. Frutos armazenados sob refrigeração apresentaram teores superiores de acidez titulável (AT) e, consequentemente, menor relação SS/AT. Os resultados, obtidos neste estudo, permitiram concluir que as modificações que ocorrem em parâmetros considerados importantes para a qualidade de physalis, como pH, AT, SS/AT, firmeza e cor, durante o período de armazenamento de frutos, podem ser minimizados com o uso da refrigeração $\left(4^{\circ} \mathrm{C}\right)$.

Palavras-chave: Physalis peruviana, frigoconservação, frutos.

\section{ABSTRACT}

\section{Post harvest quality of Cabe-gooseberry under room temperature and refrigeration}

The Cabe-gooseberry (Physalis peruviana) is a small fruit whose cultivation has been expanding in Brazil, however, information about its storage is still scarce. The aim of this study was to evaluate the quality of Cabe-gooseberry during storage at refrigerated and room temperature. The fruits were harvested when the calyx showed a greenish yellow color and submitted to the following treatments: 1 - storage at $20^{\circ} \mathrm{C}\left( \pm 0.5^{\circ} \mathrm{C}\right)$ and 2 - storage at $4^{\circ} \mathrm{C}\left( \pm 0.5^{\circ} \mathrm{C}\right)$. The quality parameters SS, TA, SS/TA, pH, firmness, color and fruit weight loss were evaluated every two days during eight days. The refrigeration promoted the maintenance of firmness and prevented the weight loss of the fruit and calyx. The soluble solids (SS) values reduced significantly, regardless of the storage temperature of the fruits. Furthermore, the fruits stored under refrigeration showed higher values of titratable acidity (TA), and therefore less SS/TA ratio. The results indicated that the changes in the quality parameters, $\mathrm{pH}, \mathrm{TA}, \mathrm{SS} / \mathrm{TA}$, firmness and color of Cabe-gooseberry during the storage can be minimized with the use of refrigeration $\left(4^{\circ} \mathrm{C}\right)$.

Key words: Physalis peruviana, cold storage, fruit.

\footnotetext{
' Engenheira-Agrônoma, Doutora. EMATER- ASCAR, Mirapalhete, 1289, 96230-000, Santa Vitória do Palmar, Rio Grande do Sul, Brasil. claudinhalim@ hotmail.com (autora correspondente).

${ }^{2}$ Engenheira Química, Doutora. Instituto Federal de Educação, Ciência e Tecnologia Farroupilha, Rua Esmeralda, 430, Faixa Nova, Camobi, 97110-767, Santa Maria, Rio Grande do Sul. Rio Grande do Sul, Brasil. joseana@sa.iffarroupilha.edu.br

${ }^{3}$ Engenheira Agrícola. Mestranda da Universidade Federal de Pelotas, Caixa Postal 354, 96001-970, Pelotas, Rio Grande do Sul, Brasil. suelenb.andrade@gmail.com

${ }^{4}$ Engenheira-Agrônoma, Mestre. Departamento de Agronomia, Universidade Federal de Pelotas, Caixa Postal 354, 96001-970, Pelotas, Rio Grande do Sul, Brasil. luanaffonso@yahoo.com.br

${ }^{5}$ Engenheiro-Agrônomo, Doutor. Departamento de Agronomia, Universidade Federal de Pelotas, Caixa Postal 354, 96001-970, Pelotas, Rio Grande do Sul, Brasil. cesarvrf@ufpel.edu.br

${ }^{6}$ Engenheira-Agrônoma, Doutora. Embrapa Uva e Vinho, Estação Experimental de Fruticultura de Clima Temperado, BR 285, Km 4, Caixa Postal 1513, Vacaria, Rio Grande do Sul, Brasil. andrea.rufato@cnpuv.embrapa.br
} 


\section{INTRODUÇÃO}

A physalis é o pequeno fruto mais exportado na Colômbia, com área plantada de 7.290 hectares e produção de 11.327 toneladas, em 2004 (Ministerio de Agricultura y Desarrollo Rural Colômbia, 2007). No Brasil, esta espécie é consumida como fruto exótico, de preço bastante elevado. Apesar da popularidade da espécie silvestre (Physalis angulata) no norte e nordeste, tanto a espécie silvestre como a domesticada (Physalis peruviana) ainda são desconhecidas no sul do país e dados a respeito de sua produção e consumo no Brasil ainda não existem. No entanto, o cultivo de $P$. peruvina vem sendo ampliado no Rio Grande do Sul, principalmente nas cidades de Áurea, Roca Sales, Vacaria e Carazinho, bem como nas cidades catarinenses de Fraiburgo e Lages (Lima et al., 2009a).

O fruto de physalis é uma baga carnosa globular, com coloração amarelo-alaranjada quando madura, com diâmetro que oscila entre 1,25 e $2,50 \mathrm{~cm}$ e peso entre quatro e dez gramas, que se desenvolve dentro de um cálice formado por cinco sépalas, que o protegem contra insetos, pássaros, patógenos e condições climáticas adversas (Velasquez et al., 2007).

Trabalhos relatam que frutos de physalis possuem altos teores de vitamina A, B e C (Puente et al. 2011; Ramadan, 2011), além de conter micronutrientes, como Fe e $\mathrm{Zn}$, e macrominerais, como o $\mathrm{P}$, e pequenas quantidades de Ca, compostos que são, sabidamente, essenciais ou necessários para o funcionamento normal do nosso corpo (Szefer \& Nriagu, 2007; Ramadan, 2011). Frutos de physalis também apresentam significativos teores de compostos fenólicos e carotenoides (Severo et al. 2010), ácidos graxos insaturados, como o ácido linoleico e fitoesteróis, predominantemente o campesterol (Valenzuela \& Ronco, 2004). Estudos vêm demonstrando que as physalinas, presentes nos frutos de physalis, são substâncias imunossupressoras importantes para inibir respostas indesejadas que ocorrem por causa de doenças autoimunes, alergias e em transplante de órgãos, além de apresentar atividade anti-câncer (Wu et al. 2004).

A colheita de physalis se inicia entre três e cinco meses após o transplante das mudas, dependendo da altitude de cultivo; quanto maior a altitude, maior será o período de tempo entre a semeadura e a colheita (Lima, 2009). Uma vez iniciada, a colheita deve ser contínua e semanal, com duração de aproximadamente seis meses. Existem vários métodos para definir o momento apropriado para realização da colheita; no entanto, a coloração do cálice é a mais observada por produtores e comerciantes (Cedeño \& Montenegro, 2004). Fischer \& Martinez (1999) e Lima et al. (2009b) demonstraram, em seus estudos, que a colheita da physalis pode ser realizada a partir do momento em que o cálice apresenta coloração ama- relo-esverdeada, com produção aproximada de dois quilogramas de frutos por planta.

Um dos fatores limitantes no manejo pós-colheita de physalis refere-se ao seu armazenamento. $\mathrm{O}$ fato de ser um fruto climatérico (Alvarado et al., 2004) e possuir período de colheita extenso dificulta seu manejo, interferindo no processo de armazenamento, transporte e vida útil pós-colheita. Aliado a isso, há insuficiência de estudos sobre armazenamento de physalis, sendo que esse conhecimento pode contribuir no manejo adequado durante as diferentes operações pós-colheita, mantendo e prolongando a qualidade e vida útil dos frutos (Galvis et al., 2005). Sabe-se que o uso de refrigeração no armazenamento de frutas, de maneira geral, é uma alternativa viável para a manutenção da qualidade pós-colheita (Brackmann et al., 2010). Estudos que buscam prolongar a conservação pós-colheita de frutos são de grande relevância, principalmente quando se trata de um pequeno fruto com alto valor agregado e grande apelo nutracêutico, como é o caso da physalis, pois deseja-se que os frutos cheguem ao consumidor com o mínimo de alterações em seu valor nutritivo, aspecto e sabor (Herrera, 2000). Por essa razão, buscou-se, neste trabalho, avaliar alguns parâmetros importantes da qualidade pós-colheita de frutos de physalis (SS, AT, SS/AT, pH, firmeza, cor e perda de massa) durante o armazenamento, em temperaturas ambiente e de refrigeração $\left(4^{\circ} \mathrm{C}\right)$.

\section{MATERIAL E MÉTODOS}

O experimento foi conduzido no Laboratório de Fisiologia Pós- Colheita de Frutas e Hortaliças - Bromatologia, do Departamento de Ciência e Tecnologia Agroindustrial, da Faculdade de Agronomia Eliseu Maciel, da Universidade Federal de Pelotas (UFPel). Foram utilizados frutos de physalis (Physalis peruviana), provenientes da coleção pertencente ao Centro Agropecuário da Palma, da UFPel, localizado no Município de Capão do Leão/RS.

A coleção utilizada nesta pesquisa é formada por 225 plantas, no espaçamento de $1 \mathrm{~m}$ entre plantas e $3,5 \mathrm{~m}$ entre linhas, e idade das plantas entre cinco e dez meses. O clima da região é do tipo "Cfa", caracterizado como temperado úmido, com verões quentes, conforme a classificação de Köppen. A região possui temperatura e precipitação média anual de $17,9^{\circ} \mathrm{Ce} 1500 \mathrm{~mm}$, respectivamente (Trewartha \& Horn, 1980).

Os frutos de physalis foram colhidos manualmente, e aleatoriamente, em diversas posições e orientações na planta, com utilização de luvas e caixas plásticas de colheita lavadas e desinfetadas. A colheita foi realizada quando a coloração do cálice estava amarelo-esverdeada, sendo confirmada a coloração dos frutos em laboratório, utilizando-se colorímetro Minolta CR-300, fonte de luz D 65 
e $8 \mathrm{~mm}$ de abertura, no padrão CIE-Lab, com duas leituras em lados opostos na região equatorial do cálice, buscando padronizar as amostras. Nesse sistema, a coordenada $\mathrm{L}^{*}$ expressa o grau de luminosidade da cor medida $\left(\mathrm{L}^{*}=\right.$ 0 , preto; 100 , branco). Os valores de $\mathrm{a}^{*}$ expressam o grau de variação entre o vermelho e o verde $\left(a^{*}\right.$ negativo $=$ verde; $a^{*}$ positivo = vermelho) $\mathrm{e}$, a coordenada $\mathrm{b}^{*}, \mathrm{o}$ grau de variação entre o azul e o amarelo $\left(b^{*}\right.$ negativo $=$ azul; $\mathrm{b}^{*}$ positivo $=$ amarelo), de acordo com Lima et al. $(2009 \mathrm{~b})$. Os valores $\mathrm{a}^{*} \mathrm{e} \mathrm{b}^{*}$ foram usados para calcular o ângulo Hue ou matiz $\left(h^{\circ}=\operatorname{tang}^{-1} b^{*} \cdot a^{*-1}\right)$ (Tabela 1$)$, foram descartados os frutos que apresentavam cálices com injúrias mecânicas, ataques fúngicos e, ou, de insetos, ou outros defeitos, uniformizando-se as amostras.

$\mathrm{Na}$ colheita, foi realizada amostragem de 40 frutos para avaliação de variáveis físico-químicas, sendo estas consideradas padrão de ponto de colheita, para posteriores comparações (Tabela 1; Tabela 2). Para avaliação do tempo e da temperatura de armazenamento, nas características física e química de physalis, frutos com cálice foram acondicionados em bandejas de poliestireno, previamente higienizadas com água clorada a 200 ppm, com capacidade de $50 \mathrm{~g}$, totalizando dez frutos por bandeja. Os frutos foram armazenados por 2, 4, 6 e 8 dias, à temperatura de $20{ }^{\circ} \mathrm{C}\left( \pm 0,5^{\circ} \mathrm{C}\right)$ e de $4{ }^{\circ} \mathrm{C}\left( \pm 0,5^{\circ} \mathrm{C}\right)$, com 90 - $95 \%$ de UR.

Após cada período de armazenamento, foram realizadas as seguintes avaliações físicas e químicas: sólidos solúveis (SS), por refratometria, com refratômetro de mesa Shimadzu, com correção de temperatura para $20^{\circ} \mathrm{C}$, utilizando-se uma gota de suco puro de cada repetição e expressando-se os resultados em ${ }^{\circ}$ Brix; acidez titulável (AT), avaliada por titulometria de neutralização, com diluição de $10 \mathrm{~mL}$ de suco puro em $90 \mathrm{~mL}$ de água destilada e titulação com solução de $\mathrm{NaOH} \quad 0,1 \mathrm{~N}$, até que o suco atingisse $\mathrm{pH} 8,1$, expressando-se o resultado em percentagem de ácido cítrico; relação SS/AT; e pH, determinado diretamente no suco dos frutos com o uso de um medidor de pH Digimed DMPH - 2, com correção automática de temperatura; firmeza dos frutos, em equipamento TA.XT plus, equipado com microcomputador, por perfurações de $10 \mathrm{~mm}$ na região equatorial dos frutos, com ponteira de 2 mm e velocidade de $1,0 \mathrm{~mm} . \mathrm{s}^{-1}$, com resultados expressos em Newton $(\mathrm{N})$; coloração do cálice e da epiderme do fruto, determinada com duas leituras, em lados opostos na região equatorial do fruto e do cálice, com o colorímetro Minolta CR- 300; perda de massa fresca dos frutos, do cálice e total (fruto, cálice e o talo), calculada a partir das diferenças de massa observadas entre o momento da instalação do experimento e a avaliação após o armazenamento; sendo os resultados expressos em percentagem $(\%)$.

O delineamento experimental foi completamente casualizado, com esquema fatorial 2 x 4, (temperaturas de armazenamento x períodos de armazenamento). Cada uma destas combinações continha quatro repetições e cada repetição foi composta por dez frutos, representando uma unidade experimental. Os dados foram submetidos à análise de variância (ANOVA) e, quando significativos, foi realizada análise de regressão, por meio do programa Winstat 2.0 (Machado \& Conceição, 2003).

\section{RESULTADOS E DISCUSSÃO}

Observou-se interação significativa entre os fatores para as variáveis $\mathrm{pH}$, perda de massa do fruto, do cálice e total. Para os demais parâmetros, as variáveis independentes atuaram de forma isolada.

O teor de sólidos solúveis da physalis apresentou redução após a colheita, sofrendo influência significativa do período de armazenamento (Tabela 2; Figura 1). Podese observar que o armazenamento refrigerado não preveniu a redução constante do teor de SS, independentemente da temperatura (Figura 1). A redução dos teores de SS em frutos de physalis durante o armazenamento já foi relatada por Ávila et al. (2006), para os quais essas res-

Tabela 1. Variáveis de cor, luminosidade (L), coordenadas a*, $\mathrm{b}^{*}$ e ângulo Hue $\left(\mathrm{h}^{\circ}\right)$ da epiderme do cálice e dos frutos de Physalis, no momento da colheita. FAEM/UFPel, Capão do Leão-RS, 2009

\begin{tabular}{|c|c|c|c|c|c|c|c|}
\hline \multicolumn{4}{|c|}{ Epiderme do Cálice } & \multicolumn{4}{|c|}{ Epiderme da Fruta } \\
\hline $\mathbf{L}^{*}$ & $\mathbf{a}^{*}$ & $\mathbf{b}^{*}$ & $\mathbf{h}^{\circ}$ & $\mathbf{L}^{*}$ & $a^{*}$ & $\mathbf{b}^{*}$ & $\mathbf{h}^{\circ}$ \\
\hline 56,22 & 0,01 & 20,66 & 109,56 & 65,49 & 7,79 & 36,75 & 77,32 \\
\hline
\end{tabular}

$\mathrm{L}^{*}(0=$ preto, $100=$ branco $) ; \mathrm{a}^{*}(+\mathrm{a}=$ vermelho, - $\mathrm{a}=$ verde $) ; \mathrm{b}^{*}(+\mathrm{b}=$ amarelo, $-\mathrm{b}=$ azul $) ;$ ângulo $\mathrm{h}^{\circ}\left(0^{\circ}=\right.$ vermelho, $90^{\circ}=$ amarelo, $180^{\circ}$ $=$ verde, $360^{\circ}=$ azul $)$.

Tabela 2. Variáveis físico-químicas na caracterização de Physalis no momento da colheita. FAEM/UFPel, Capão do Leão-RS, 2009

\begin{tabular}{|c|c|c|c|c|c|c|c|}
\hline SS $\left({ }^{\circ}\right.$ Brix $)$ & $\begin{array}{c}\text { AT } \\
(\% \text { ac.Cítrico })\end{array}$ & $\begin{array}{l}\text { Relação } \\
\text { SS/AT }\end{array}$ & $\mathrm{pH}$ & $\begin{array}{l}\text { Firmeza } \\
(\mathbf{N})\end{array}$ & \multicolumn{3}{|c|}{ Massa (g) } \\
\hline & & & & & Cálice & Fruto & Total \\
\hline 14,0 & 0,89 & 15,73 & 3,59 & 1,28 & 2,90 & 5,01 & 8,00 \\
\hline
\end{tabular}


postas podem ser atribuídas ao aumento da intensidade respiratória dos frutos, uma vez que parte dos açúcares é utilizada no processo respiratório (Trinchero et al., 1999).

A acidez titulável dos frutos foi influenciada pela temperatura de armazenagem, ocorrendo redução após a colheita; entretanto, não foi significativamente influenciada pelo período de armazenamento (Tabela 1; Tabela 3). A maior AT apresentada pelos frutos armazenados sob refrigeração ocorreu, provavelmente, em decorrência da baixa temperatura a que os frutos foram expostos, que diminui o metabolismo do fruto, reduzindo a síntese de açúcares e, consequentemente, a utilização dos ácidos orgânicos (Alvarado et al., 2004).

A relação SS/AT também não foi significativamente influenciada pelo período de armazenamento; todavia sofreu influência significativa da temperatura durante a armazenagem, sendo as maiores médias obtidas nos frutos armazenados em temperatura ambiente, concordando com os menores teores de AT apresentado por esses frutos (Tabela 3). Apesar de os teores de SS não terem sido significativamente afetados pela refrigeração (Figura 1), os teores de AT o foram, o que influenciou significativamente a relação (SS/AT) (Tabela 3). Por ser a relação desses

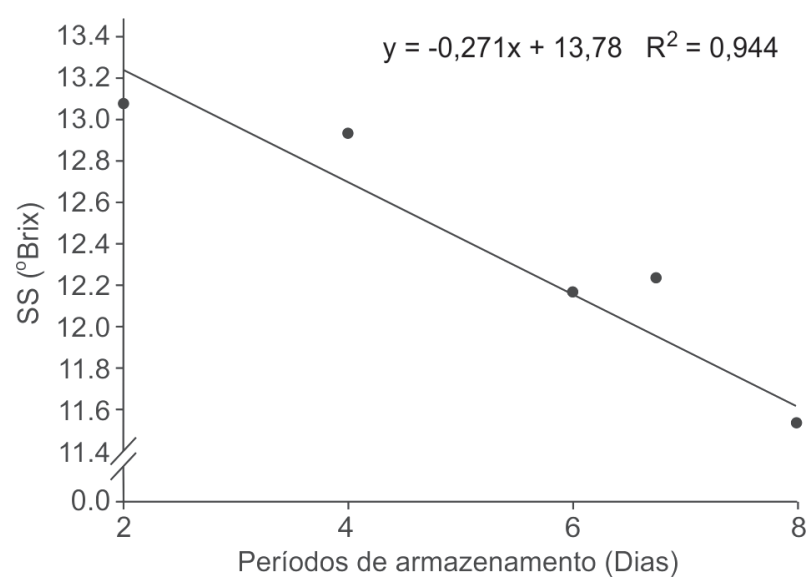

Figura 1. Teor de sólidos solúveis (SS) de frutos de Physalis em função de quatro períodos de armazenamento. FAEM/UFPel, Capão do Leão-RS, 2009. dois importantes índices de maturação de frutos, teor de SS e AT, pode-se afirmar que a relação SS/AT fornece uma indicação de maturação/qualidade mais completa para os frutos de physalis. Desse modo, valores menores, apresentados por frutos armazenados sob refrigeração, refletem o efeito das baixas temperaturas na redução do processo de amadurecimento de frutos climatéricos.

Não houve grande variação de $\mathrm{pH}$, durante o armazenamento à temperatura ambiente. Porém, quando os frutos foram armazenados sob refrigeração, no quarto dia, observou-se uma significativa redução do $\mathrm{pH}$, com elevação a partir do sexto dia (Tabela 2; Figura 2). A redução brusca do pH, observada no quarto dia de armazenamento, pode ser decorrente da influência da refrigeração no metabolismo do fruto; já o aumento do $\mathrm{pH}$, no final do armazenamento, concorda com os dados de Novoa et al. (2006), que relatam que os frutos de physalis seguem a tendência dos processos de maturação, tornando-se menos ácidos com o passar do tempo de armazenagem, graças ao desdobramento de ácidos orgânicos como substrato respiratório.

$\mathrm{O}$ uso de baixa temperatura $\left(4^{\circ} \mathrm{C}\right)$ também colaborou significativamente para a manutenção da firmeza dos frutos após a colheita, embora os períodos de armazenamento não tenham afetado significativamente essa variável (Tabela 2; Tabela 3). A manutenção da firmeza, observada nos frutos de physalis armazenados sob refrigeração, pode ser relacionada com o retardo do processo natural de senescência, que promove o abrandamento da rigidez celular do fruto em decorrência da degradação de carboidratos e carbono poliméricos, especificamente, substâncias pécticas e hemicelulares, as quais debilitam as forças coesivas entre células e parede celular (Ciro \& Osório, 2008).

Quando verificada a coloração da epiderme dos frutos, observa-se que, na colheita, os valores do ângulo Hue, luminosidade, coordenada $\mathrm{a}^{*} \mathrm{e} \mathrm{b}^{*}$ foram inferiores aos encontrados durante o armazenamento (Tabela 1; Tabela 3). Os frutos armazenados sob refrigeração apresentaram menores valores para coordenada $\mathrm{a}^{*}$, indicando que os frutos apresentavam menor intensidade de vermelho, provavel-

Tabela 3. Acidez titulável (\% ac. cítrico), relação (SS/AT), firmeza de polpa (N), luminosidade (L), coordenadas a*, b*e ângulo Hue $\left(\mathrm{h}^{\circ}\right)$ da epiderme da fruta em frutos de Physalis em função de duas temperaturas de armazenamento. FAEM/UFPel, Pelotas, RS, 2009

\begin{tabular}{|c|c|c|c|c|c|c|c|}
\hline \multirow{2}{*}{$\begin{array}{l}\text { Temperaturas de } \\
\text { armazenamento } \\
\left({ }^{\circ} \mathrm{C}\right) \\
\end{array}$} & \multirow{2}{*}{$\begin{array}{l}\mathrm{AT}(\% \text { ac. } \\
\text { Cítrico })\end{array}$} & \multirow{2}{*}{$\begin{array}{l}\text { Relação } \\
\text { SS/AT }\end{array}$} & \multirow{2}{*}{$\begin{array}{c}\text { Firmeza de } \\
\text { polpa }(\mathbf{N})\end{array}$} & \multicolumn{4}{|c|}{ Coloração da epiderme da fruta } \\
\hline & & & & $\mathbf{L}^{*}$ & $\mathbf{a}^{*}$ & $\mathbf{b}^{*}$ & $\mathbf{h}^{\circ}$ \\
\hline $\begin{array}{l}\text { Temperatura } \\
\text { Refrigerada }\left(4^{\circ} \mathrm{C}\right)\end{array}$ & $0,85 \mathrm{a}$ & $14,66 \mathrm{~b}$ & $1,22 \mathrm{a}$ & $67,93 \mathrm{a}$ & $8,15 \mathrm{~b}$ & $56,63 \mathrm{a}$ & 79,88 a \\
\hline $\begin{array}{l}\text { Temperatura } \\
\text { Ambiente }\left(20^{\circ} \mathrm{C}\right)\end{array}$ & $0,73 \mathrm{~b}$ & 17,62 a & $0,83 \mathrm{~b}$ & $66,44 \mathrm{~b}$ & $10,38 \mathrm{a}$ & $45,06 \mathrm{~b}$ & $77,61 \mathrm{~b}$ \\
\hline$\overline{\mathrm{CV}(\%)}$ & 10,88 & 13,43 & 14,13 & 2,25 & 13,00 & 4,25 & 3,28 \\
\hline
\end{tabular}

$\mathrm{L}^{*}(0=$ preto, $100=$ branco $) ; \mathrm{a}^{*}(+\mathrm{a}=$ vermelho, $-\mathrm{a}=$ verde $) ; \mathrm{b}^{*}(+\mathrm{b}=$ amarelo, $-\mathrm{b}=$ azul $) ;$ ângulo $\mathrm{h}^{\circ}\left(0^{\circ}=\right.$ vermelho, $90^{\circ}=$ amarelo, $180^{\circ}$ $=$ verde, $360^{\circ}=$ azul). $*$ Médias seguidas de mesma letra minúscula na coluna não diferem entre si pelo teste de Tukey $(\mathrm{p} \leq 0,05)$. 
mente em decorrência do atraso no acúmulo de compostos carotenoides, responsáveis pela pigmentação desse fruto, e que sua biossíntese é negativamente influenciada pela redução da temperatura de armazenamento (Severo et al. 2010). Entretanto, as maiores médias para os demais parâmetros foram obtidas quando os frutos foram armazenados à temperatura de $4{ }^{\circ} \mathrm{C}$. Essas informações indicam que os frutos armazenados nesta condição apresentavam coloração laranja $\left(79,82^{\circ} \mathrm{Hue}\right)$, com coloração mais amarela $\left(56,63 b^{*}\right)$ e mais brilhante $(67,93 \mathrm{~L})$ (Tabela 3$)$.

Em relação à coloração do cálice, o período de armazenamento foi o fator que exerceu maior influência (Tabela 4). As variáveis luminosidade e coordenada b* apresentaram diferenças significativas entre os períodos de armazenamento, sendo verificado, a partir do quarto dia, cálice com coloração amarela mais brilhante (maior luminosidade) e, no oitavo dia, a maior intensidade amarela dos frutos (maior $b^{*}$ ). Como o observado para a coordenada $a^{*}$, a diminuição no valor da coordenada $b^{*}$, no quarto e sexto dias, pode ser associada à influência da baixa temperatura na biossíntese dos carotenoides (Severo et al. 2010). Verificou-se, ao final do período de armazenamento, que os cálices apresentavam coloração amarelo amarronzada

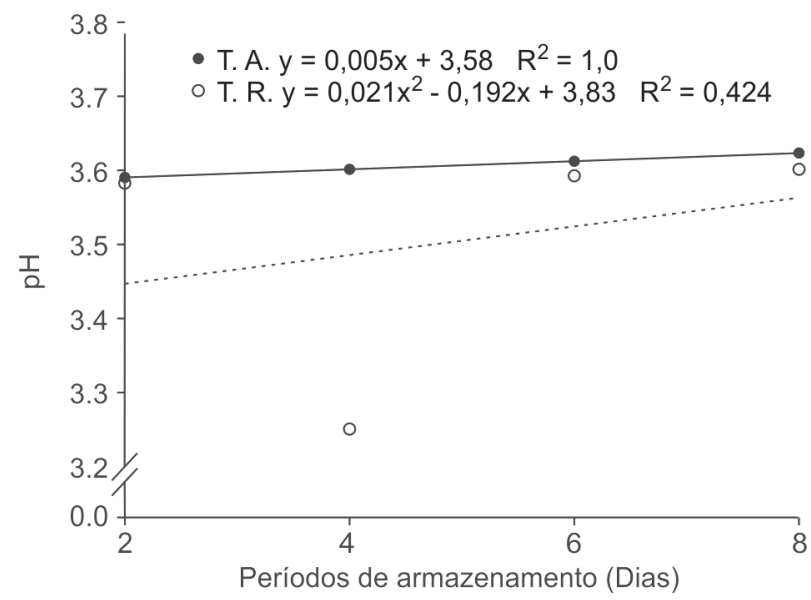

Figura 2. pH de frutos de Physalis em função da armazenamento em temperaturas ambiente (T.A.) e refrigerada (T.R.) em quatro períodos de armazenamento. FAEM/UFPel, Capão do LeãoRS, 2009.
(Tabela 4). A alteração de cor da epiderme dos frutos e do cálice está envolvida com a degradação da clorofila, assim como a síntese de outros pigmentos, como carotenoides. Para physalis, geralmente, a colheita é realizada quando o cálice e o fruto apresentam cores mais claras (amareloesverdeado, para o cálice, amarelo, para o fruto). Cores mais fortes são observadas durante e após o período de armazenamento (amarelo- amarronzado, para o cálice, e alaranjado, para o fruto), em decorrência do acúmulo de pigmentos como os carotenoides (Alvarado et al., 2004; Lima et al. 2009b; Severo et al. 2010).

Um dos maiores problemas na pós-colheita é a alta susceptibilidade da maioria dos frutos à perda de massa (Mitchell, 1992), que, além de interferir na qualidade visual do fruto, promove perdas econômicas para os produtores. Foi observado, neste experimento, que a perda de massa total do fruto e do cálice aumentou com o prolongamento do período de armazenamento para as duas temperaturas utilizadas. Essas perdas superiores e crescentes quando os frutos foram armazenados à temperatura ambiente (Figura 3; Figura 4; Figura 5), sendo que, no $8^{\circ}$ dia, foram observados os maiores índices de perda de massa total, do fruto e do cálice. De maneira geral, quan-

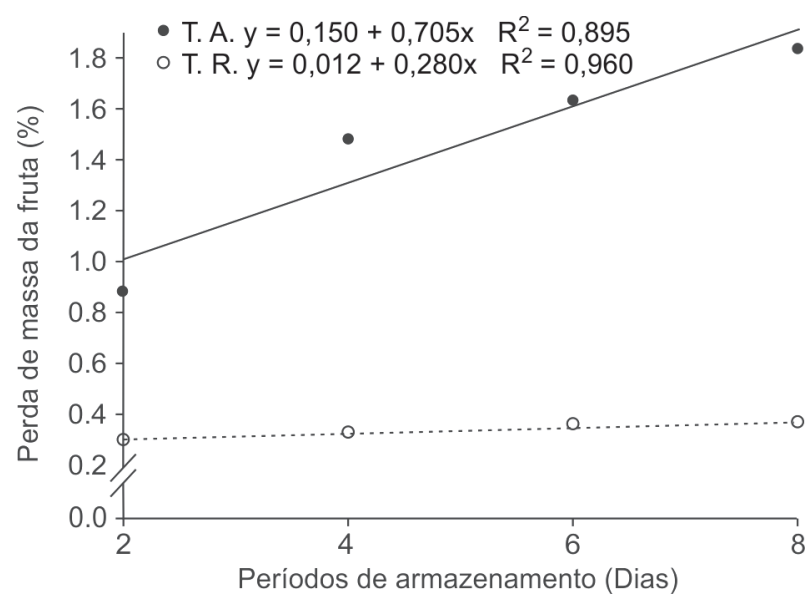

Figura 3. Perda de massa da fruta de Physalis em função dos armazenamentos em temperatura ambiente (T.A.), temperatura refrigerada (T.R.) e quatro períodos de armazenamento. FAEM/ UFPel, Capão do Leão-RS, 2009.

Tabela 4. Variáveis de cor, luminosidade (L), coordenadas $\mathrm{a}^{*}, \mathrm{~b}^{*}$ e ângulo Hue $\left(\mathrm{h}^{\circ}\right)$ do cálice dos frutos de physalis, em função de quatro períodos de armazenamento. FAEM/UFPel, Capão do Leão-RS, 2009

\begin{tabular}{lcccc}
\hline $\begin{array}{l}\text { Períodos de armazenamento } \\
\text { dias) }\end{array}$ & \multicolumn{4}{c}{ Coloração do cálice } \\
\cline { 2 - 5 } & $\mathbf{L}^{*}$ & $\mathbf{a}^{*}$ & $\mathbf{b}^{*}$ & $\mathbf{h}^{\circ}$ \\
\hline 2 & $48.22 \mathrm{~b}$ & $0.01 \mathrm{a}$ & $20.00 \mathrm{a}$ & 109.56 \\
4 & $57.14 \mathrm{a}$ & $-12.35 \mathrm{a}$ & $14.59 \mathrm{~b}$ & $90.58 \mathrm{a}^{\mathrm{a}}$ \\
6 & $54.15 \mathrm{a}$ & $-10,51 \mathrm{a}$ & $15.00 \mathrm{~b}$ & $89.05^{\mathrm{a}}$ \\
8 & $55.98 \mathrm{a}$ & $2.61 \mathrm{a}$ & $20.06 \mathrm{a}$ & $79.38^{\mathrm{a}}$ \\
\hline
\end{tabular}

\begin{tabular}{|c|c|c|c|}
\hline $\mathrm{CV}(\%)$ & 2,22 & 15,72 & 3,27 \\
\hline
\end{tabular}


do as perdas superam 3-10\% da massa dos frutos, desaparece o aspecto fresco dos produtos vegetais (Burg, 2004); no entanto, neste estudo, a perda de massa não chegou a atingir $3 \%$, em ambas as condições de armazenamento, até o $8^{\circ}$ dia. Sabe-se que a diminuição da massa dos frutos pode ser em grande parte associada à perda de água por transpiração e, em menor grau, pela respiração (Kays, 1997), intensificando-se quando os frutos estão expostos a temperaturas maiores.

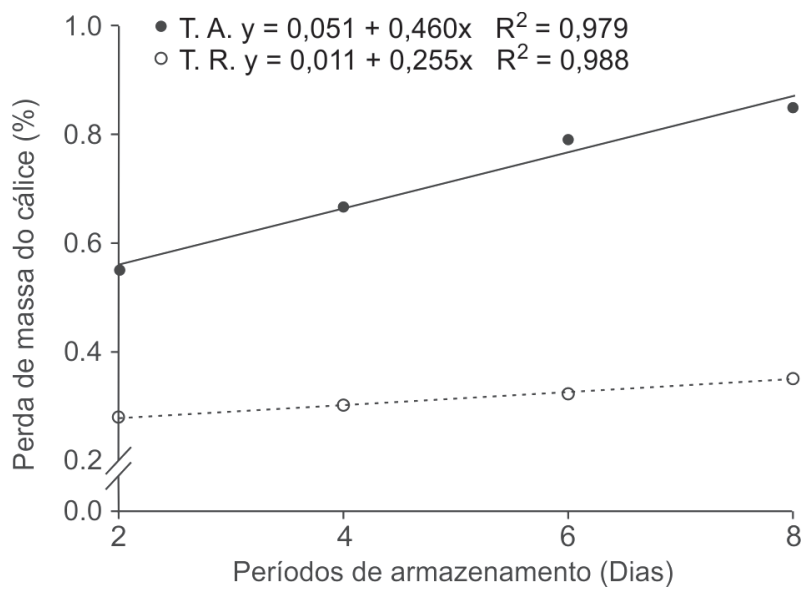

Figura 4. Perda de massa do cálice de Physalis em função dos armazenamentos em temperatura ambiente (T.A.), temperatura refrigerada (T.R.) e quatro períodos de armazenamento. FAEM/ UFPel, Capão do Leão-RS, 2009.

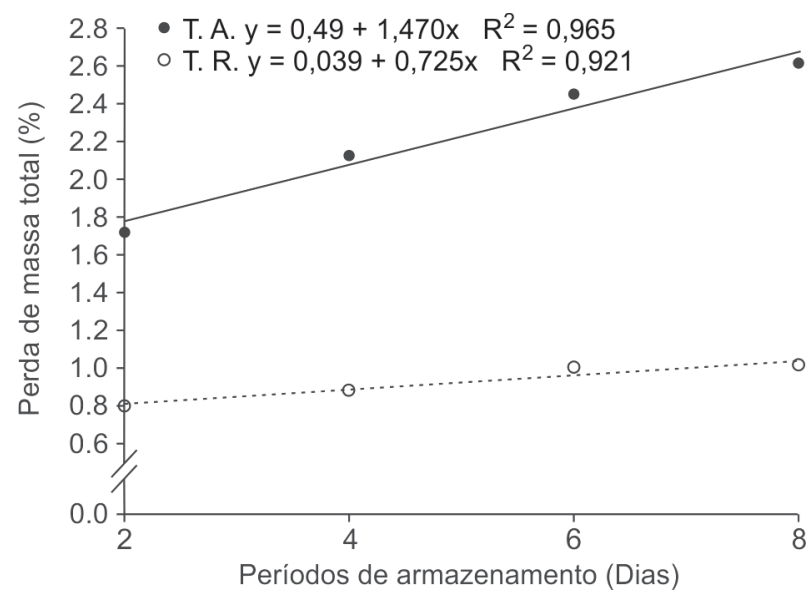

Figura 5. Perda de massa total de Physalis em função da temperatura ambiente (T.A.), temperatura refrigerada (T.R.) e quatro períodos de armazenamento. FAEM/UFPel, Capão do Leão-RS, 2009.

\section{CONCLUSÕES}

A refrigeração $\left(4^{\circ} \mathrm{C}\right)$ apresentou-se como uma alternativa viável para o armazenamento de frutos de physalis pelo período de oito dias, apresentando melhor manutenção das principais variáveis físico-químicas avaliadas neste estudo, pH, AT, SS/AT, firmeza e cor, e que estão relacionadas com a qualidade de pós-colheita desses frutos no armazenamento.

\section{REFERÊNCIAS}

Alvarado PA, Berdugo CA \& Fischer G (2004) Efecto de un tratamiento de frío $\left.(a), 5^{\circ} \mathrm{C}\right)$ y la humedad relativa sobre las características físico-químicas de frutos de uchuva Physalis peruviana $\mathrm{L}$. durante el posterior transporte y almacenamiento. Agronomía Colombiana, 22:147-159.

Ávila AJ, Moreno P, Fischer G \& Miranda D (2006) Influencia de la madurez del fruto y del secado del cáliz en uchuva (Physalis peruviana L.), almacenada a $18^{\circ} \mathrm{C}$. Acta Agronômica Colombiana, 55:29-38

Brackmann A, Anese RO, Giehl RFH, Weber A, Eisermann AC \& Sestari I (2010) Pré-resfriamento para conservação pós-colheita de melões Cantaloupe 'Hy Mark'. Bragantia, 70:672676.

Burg SP (2004) Postharvest physiology and hypobaric storage of fresh produce. Wallingford, CABI Publishing. 654p.

Cedeño MM \& Montenegro DM (2004) Plan exportador, logistico y de comercilizacion de uchuva al mercado de estados unidos para frutexpo S.C.I. Ltda. Monagrafia de conclusão de curso Pontificia Universidad Javeriana, Bogotá. 134p.

Ciro HJV \& Osório JAS (2008) Avance experimental de la ingeniería de postcosecha de frutas colombianas: resistencia mecánica para frutos de uchuva (Physalis peruviana 1). Dyna, 154:39-46.

Fischer G \& Martínez O (1999) Calidad y madurez de la uchuva (Physalis peruviana L.) emrelación con la coloracióndel fruto. Agronomía Colombiana, 16:35-39.

Galvis JA, Fischer G \& Gordillo OP (2005) Cosecha y poscosecha de la uchuva. In: Fisher G, Miranda D, Piedrahita W \& Romero J (Eds.) Avances en cultivo, poscosecha y exportación de la uchuva (Physalis peruviana L.) em Colombia. Bogotá, Unibiblos, Universidad Nacional de Colombia. p.165-190.

Herrera A (2000) Manejo poscosecha In: Flórez VJ, Fischer G \& Sora AD (Eds.) Producción, poscosecha y exportación de la uchuva (Physalis peruviana L.). Bogotá, Unibiblos, Universidad Nacional de Colombia. p.109-127.

Kays S (1997) Postharvest physiology of perishable plant products. Georgia, Exon Press. p.263-278.

Lima CSM (2009) Fenologia, sistemas de tutoramento e produção de Physalis peruviana na região de Pelotas, RS. Dissertação de Mestrado. Faculdade de Agronomia Eliseu Maciel. Universidade Federal de Pelotas, Pelotas. 116p.

Lima CSM, Manica-Berto R, Silva SJP, Betemps DL \& Rufato AR (2009a) Custos de implantação e condução de pomar de Physalis na região sul do estado do Rio Grande do Sul. Revista Ceres, $56: 555-561$

Lima CSM, Severo J, Manica-Berto R, Silva JA, Rufato L \& Rufato AR (2009b) Características físico-químicas de physalis em diferentes colorações do cálice e sistemas de condução. Revista Brasileira de Fruticultura, 31:1061-1068.

Machado AA \& Conceição AR (2003) Sistema de análise estatística para Windows: WinStat. Versão 2.0. Pelotas, UFPel.

Ministerio de Agricultura y Desarrollo Rural de Colombia y CCI (2007) Sistema de inteligência de mercados: información de monitoreo internacional. Disponível em: <http:// www.agronet.gov.co/www/docs_agronet/ 2006427154348_UCHUVAmarzo.pdf > Acessado em: 12 dezembro de 2012.

Mitchell GF (1992) Postharvest handling systems: small fruits (table grapes, strawberries, kiwifruit). In: Kader AA (Ed.) Postharvest technology of horticultural crops. $2^{\text {a }}$ ed. Davis, University of Calofornia. p.223-231. 
Novoa RM, Bojacá J, Galvis Y \& Fischer G (2006) La madurez del fruto y el secado Del cáliz influyen en el comportamiento poscosecha de la uchuva (Physalis peruviana L.) almacenada. Agronomía Colombiana, 24:77-86.

Puente LA, Pinto-Muñoz CA, Castro ES \& Cortés M (2011) Physalis peruviana Linnaeus, the multiple properties of a highly functional fruit: A review. Food Research International, 44:1733-1740.

Ramadan MF (2011) Bioactive phytochemicals, nutritional value, and functional properties of cape gooseberry (Physalis peruviana): An overview. Food Research International, 44:1830-1836.

Szefer P \& Nriagu J (2007) Mineral components in foods. New York, CRC Press. 480p.

Severo J, Lima CSM, Coelho MT, Rufatto AR \& Rombaldi CV \& Silva JA (2010) Atividade antioxidante e fitoquímicos em frutos de physalis (Physalis peruviana, L.) durante o amadurecimento e o armazenamento. Revista Brasileira de Agrociência, 16:77-82.

Trewartha GT \& Horn LH (1980) An introduction to climate. 5.ed., New York, McGraw-Hill. 416p.
Trinchero GD, Sozzi GO, Cerri AM, Vilella F \& Fraschina AA (1999) Ripening-related changes in ethylene production, respiration rate and cell-wall enzyme activity in goldenberry (Physalis peruviana L.), a solanaceous species. Postharvest Biology and Technology, 16:139-145.

Valenzuela A \& Ronco A (2004) Fitoesteroles y fitoestanoles: aliados naturales para la proteccion de la salud cardiovascular. Revista Chilena de Nutrición, 21:161-169.

Velasquez HJC, Giraldo OHB \& Arango SSP (2007) Estudio preliminar de la resistencia mecánica a la fractura y fuerza de firmeza para frut fruta de uchuva (Physalis peruviana L.). Revista Facultad Nacional de Agronomía, 60:3785-3796.

Wu SJ, Ng LT, Lin DL, Wang SS \& Lin CC (2004) Physalis peruviana extract induces apoptosis in human Hep G2 cells through CD95/CD95L system and mitochondrial signalling transduction pathway. Cancer Letters Shannon, 215:199-208. 